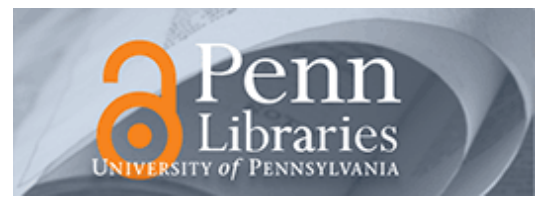

University of Pennsylvania ScholarlyCommons

5-1-2009

\title{
Views of Intimate Partner Violence in Same- and Opposite-Sex Relationships
}

Susan B. Sorenson

University of Pennsylvania, sorenson@sp2.upenn.edu

Kristie A. Thomas

Follow this and additional works at: https://repository.upenn.edu/spp_papers

Part of the Public Affairs, Public Policy and Public Administration Commons

\section{Recommended Citation}

Sorenson, S. B., \& Thomas, K. A. (2009). Views of Intimate Partner Violence in Same- and Opposite-Sex Relationships. Retrieved from https://repository.upenn.edu/spp_papers/161

This is a pre-peer reviewed version of the following article:

Sorenson, S. B., \& Thomas, K. A. (2009). Views of intimate partner violence in same- and opposite-sex relationships. Journal of Marriage and Family, 71(2), 337-352. doi: 10.1111/j.1741-3737.2009.00602.x, which has been published in final form at http://dx.doi.org/10.1111/j.1741-3737.2009.00602.x

This paper is posted at ScholarlyCommons. https://repository.upenn.edu/spp_papers/161

For more information, please contact repository@pobox.upenn.edu. 


\title{
Views of Intimate Partner Violence in Same- and Opposite-Sex Relationships
}

\begin{abstract}
Attitudes toward same-sex intimate relationships and toward intimate partner violence (IPV) are changing. Little research, however, has examined norms about IPV in same-sex relationships. Using a fractional factorial (experimental vignette) design, we conducted random-digit-dialed interviews in four languages with 3,679 community-residing adults. Multivariate analyses of responses to 14,734 vignettes suggest that IPV against gay male, lesbian, and heterosexual women is more likely than that against heterosexual men to be considered illegal, that it should be illegal, police called, and a stay-away order issued. Regardless of gender and sexual orientation, the type of abuse and whether a weapon was displayed are the strongest predictors of respondents' judgments about whether a behavior is illegal and merits a range of societal interventions.
\end{abstract}

\section{Keywords}

community, experimental methods, gay/lesbian/bisexual/transgender, intimate partner/marital abuse, violence, survey research

Disciplines

Public Affairs, Public Policy and Public Administration | Social and Behavioral Sciences

\section{Comments}

This is a pre-peer reviewed version of the following article:

Sorenson, S. B., \& Thomas, K. A. (2009). Views of intimate partner violence in same- and opposite-sex relationships. Journal of Marriage and Family, 71(2), 337-352. doi: 10.1111/j.1741-3737.2009.00602.x, which has been published in final form at http://dx.doi.org/10.1111/j.1741-3737.2009.00602.x 
Running head: VIEWS OF SAME- AND OPPOSITE-SEX PARTNER VIOLENCE

Views of Intimate Partner Violence in Same- and Opposite-Sex Relationships

\author{
Susan B. Sorenson and Kristie A. Thomas \\ School of Social Policy and Practice \\ University of Pennsylvania
}

Author contact information:

3815 Walnut Street, Philadelphia, PA 19104

e-mail: sorenson@sp2.upenn.edu and kristiet@sp2.upenn.edu

phone: $215.573-1169$

Acknowledgment

The data used in this research were obtained through a grant funded by the California Department of Health Services (CHDS). The work reported is that of the author; it is not the work of, nor does it represent the views of, CDHS.

Thanks to the National Opinion Research Center for its multiple efforts, members of the community advisory panel (Brenda Aris, Richie Cole, Charles Hall, Alva Moreno, Nilda Rimonte, Rosario Roberts, and Bernita Walker), staff of the California Department of Health Services, and the California residents who participated in the survey. 


\begin{abstract}
Attitudes toward same-sex intimate relationships and toward intimate partner violence (IPV) are changing. Little research, however, has examined norms about IPV in same-sex relationships. Using a fractional factorial (experimental vignette) design, we conducted random-digit-dialed interviews in four languages with 3,679 community-residing adults. Multivariate analyses of responses to 14,734 vignettes suggest that IPV against gay male, lesbian, and heterosexual women is more likely than that against heterosexual men to be considered illegal, that it should be illegal, police called, and a stay-away order issued. Regardless of gender and sexual orientation, the type of abuse and whether a weapon was displayed are the strongest predictors of respondents' judgments about whether a behavior is illegal and merits a range of societal interventions.
\end{abstract}

Keywords: Community < Social context; Experimental methods < Method; Gay, lesbian, bisexual transgender < Family structure; Intimate partner/marital abuse < Violence; Survey research $<$ Method 
Since its inception as a topic of scholarly inquiry, the definition of what constitutes violence against an intimate has evolved from physical assault alone to include sexual assault, psychological maltreatment, and stalking. Moreover, the term "domestic violence," which is widely used and largely associated with married heterosexual couples, has been supplanted in some quarters by the term "intimate partner violence" (IPV) so as to explicitly include people who are in nonmarital relationships, for example, dating adolescents, divorced women, and lesbians and gay men.

As views of violence in intimate relationships are changing, so are perceptions of samesex relationships. Concomitant with more positive attitudes toward gay men and lesbians and their sexual behavior during the past generation (Hicks \& Lee, 2006; Treas, 2002), national polls document dramatically increased support of civil unions, inheritance rights and Social Security benefits for gay male and lesbian partners (Brewer \& Wilcox, 2005). There are limits, however. A majority of Americans believe that same-sex marriage undermines traditional family values and do not support same-sex marriage (Brewer \& Wilcox, 2005; Schmitt, Lehmiller, \& Walsh, 2007). And, Americans remain divided on the issue of whether children should be adopted by same-sex couples (Pew Research Center, 2006).

Those who hold more negative views about gay men and lesbians are those with less formal education (Ohlander, Batalova, \& Treas, 2005), higher religiosity (Hicks \& Lee, 2006), stronger adherence to traditional male and female roles (Hicks \& Lee, 2006), and little personal contact with gay men and lesbians (Herek \& Glunt, 1993). Anti-gay sentiment is believed to be strong in minority communities (Diaz, Ayala, Bein, Henne, \& Marin, 2001; Mays \& Cochran, 2001; Wilson \& Yoshikawa, 2004); nonetheless, some of these same groups favor protections against discrimination on the basis of sexual orientation (Lewis, 2003). Many of the participants 
in the present investigation are immigrants, so it may be useful to note that acceptance of samesex intimate relationships varies substantially around the world. People in Africa and the Middle East strongly object to same-sex intimate relationships whereas major Latin American countries and Western European countries are much more accepting (Pew Global Attitudes Project, 2003).

Gender also plays a role in attitudes about intimate same-sex relationships. As a group, heterosexual men generally hold more negative attitudes about gay men and lesbians than do heterosexual women. Men and women hold similar attitudes about lesbians but men (vs. women) hold harsher attitudes toward gay men (Hicks \& Lee, 2006; Ratcliff, Lassiter, Markman, \& Snyder, 2006).

\section{Intimate Partner Violence among Lesbians and Gay Men}

Research to date suggests that lesbians and gay men report a nature and scope of IPV similar to that reported by heterosexual women: psychological abuse is the most common form of IPV, multiple forms of abuse are relatively typical, and IPV becomes more frequent and severe over time (Bradford, Ryan, \& Rothblum, 1994; Craft \& Serovich, 2005; Greenwood et al., 2002; Lie \& Gentlewarrier, 1991; Lockhart, White, Causby, \& Issac, 1994; McClennen, Summers, \& Vaughan, 2002; Merrill \& Wolfe, 2000). Despite attempts to recruit representative samples, each of these studies consisted primarily of educated and employed Whites who selfidentified as being a gay man or lesbian.

Using a nationally representative sample, the National Violence Against Women Survey (NVAWS), examined IPV in same-sex relationships based not on self-identification as being gay or lesbian but on behavior, that is, whether a respondent had ever lived with a same-sex partner "as a couple" (Tjaden, Thoennes, \& Allison, 1999). Lifetime rates of physical and/or sexual IPV were almost twice as high for women who had ever cohabited with a female intimate as for 
women who had cohabited only with a male intimate $(39.2 \%$ and $20.3 \%$, respectively), which might lead some to conclude that lesbian relationships are more likely than heterosexual ones to be violent. However, the NVAWS also asked about assailant gender, which proved useful: Women who had lived with a female partner were substantially less likely to report abuse by a female intimate $(11.4 \%)$ than opposite-sex cohabiting women reported abuse by a male intimate $(20.3 \%)$. Thus, the higher rate of victimization among women who had ever lived with a female intimate resulted from experiences of abuse at the hands of male, not female, intimates.

The NVAWS showed that asking about assailant gender is important in studies of IPV because doing so acknowledges the reality that many individuals living in intimate same-sex relationships have had intimate opposite-sex relationships and vice versa (e.g., Diamant, Schuster, McGuigan, and Lever, 1999). Asking about assailant gender can help researchers more adequately discern patterns of IPV victimization in that it avoids confounding victimization history with a respondent's behavior (e.g., current or former living arrangements, having had sex with a person of the same sex) or self identification. The NVAWS investigators rightly noted the limitations inherent in categorizing respondents based on their cohabitation history and cautioned that additional research - research that includes those who identify as gay or lesbian but who have not lived as a couple with someone of the same sex - is needed before statements can be made about IPV among gay men and lesbians in general.

\section{Societal Views of Intimate Partner Violence among Gays and Lesbians}

Few empirical studies investigating societal attitudes toward gay and lesbian IPV have been published. We limit our review of research on the topic to studies using experimental vignette methods because few other designs have been used and because experimental vignettes are methodologically superior to simple direct questioning. Vignette designs are used to reduce 
social desirability in responses and to better understand contextual factors that are taken into consideration when judgments are made. When levels of the variables in the vignettes are randomly assigned by the investigator, the design is known as an experimental vignette or factorial design (Rossi \& Anderson, 1982). These designs are considered by some to be the "gold standard" design when assessing norms. The use of experimental vignettes in studies on IPV allows researchers to manipulate characteristics of the assault and the people involved, and to measure the characteristics of the respondents in order to better understand the factors that influence judgments about IPV.

The first, to our knowledge, factorial study to include a scenario about a gay male victim of IPV was published in the mid-1990s (Harris \& Cook, 1994). Although participants reported liking the gay victim the least, their ratings of the gay vignette ranked between those for wife battering (seen as the most wrong) and husband battering (considered the least wrong). The few subsequent studies continued to rely primarily on samples of mostly White Midwestern undergraduates and to focus solely on gender, but they attempted to address previously identified limitations most notably by including a vignette about IPV among lesbians (Poorman, Seelau, \& Seelau, 2003; Seelau, Seelau, \& Poorman, 2003; Seelau \& Seelau, 2005). Although participants rated heterosexual victims as more believable than gay male and lesbian victims (Poorman et al., 2003), most of the findings from these investigations indicated that respondents made similar judgments about gay male, lesbian, and male-on-female intimate partner violence.

Respondent gender was a significant predictor of responses to IPV scenarios. Men were less likely to want the police called and more likely to recommend leaving the couple alone regardless of victim gender (Seelau et al., 2003). Women were more supportive of system intervention, but only for female victims; in cases with male victims they preferred to leave the 
couple alone. Respondent gender was unrelated to victim sexual orientation in judgments about the behavior and preferred responses to the scenarios.

Why This Study?

Victimization is, at least partly, a social construction and society and its agents tend to perceive some victims as more worthy than others. Previous research provides limited guidance by which to hypothesize the nature of norms about IPV among gay men and lesbians. For example, race is important in the application of the death penalty: Regardless of their own race, those who kill a White person are more likely to be sentenced to death (Baldus, Woodworth, \& Pulaski, 1990). Such a finding suggests that IPV will be judged more harshly when a heterosexual man is the victim. However, recent research indicates that, with a few exceptions, respondents give higher seriousness ratings to incidents involving minority, including women and same-sex, victims (Lyons, 2008). Thus, gays and lesbians are perceived as more worthy victims. Nonetheless, when demographic characteristics are similar between a victim and perpetrator, violent acts seem to elicit less outrage and less willingness to get involved, as historically has been the case with Black-on-Black homicide (Bell, 1987). Thus, given the manon-man and woman-on-woman nature of IPV in the relationships of gay men and lesbians, gay men and lesbian IPV victims may be seen as less worthy victims. And, the exclusion of gay men and lesbians from original constructions of the definition of an IPV victim (Letellier, 1994), may further contribute to assessments of lesbian and gay male victims as being less worthy victims. Moreover, prior research, as reviewed above, suggests that heterosexual men may be the ones who are seen as less worthy victims in cases of IPV. Thus, we investigated the characteristics of those deemed to be worthy victims.

The present investigation contributes to the literature through the use of a sample of community-residing adults that was diverse in education, age, ethnicity, language, and a host of 
other demographic characteristics. It also contributes to the literature in that it expanded prior applications of experimental vignette methods to the topic by measuring characteristics of the respondents and by randomly varying multiple considerations about the victim, the assailant, the context of the IPV incident (e.g., age, ethnicity, nature of the behavior, alcohol use, frequency). These additional variables were included because they each had the potential to affect respondent judgments and, therefore, merited investigation. And, finally, as noted above, the work addresses competing perspectives about who constitutes a worthy victim, a largely unexplored topic in IPV among sexual minorities.

We addressed four research questions: 1) Does sexual orientation (i.e., same vs. opposite sex) of the couple affect judgments about IPV?, 2) Does victim gender enter into judgments about IPV in same-sex and opposite-sex relationships?, 3) Do victim sexual orientation and gender affect the contextual characteristics that are taken into consideration in judgments about IPV?, and 4) What respondent characteristics are related to their judgments about IPV in sameand opposite-sex relationships?

\section{Method}

The data for this study are from a survey of norms about intimate partner violence among six samples of community-residing adults ( $\geq 18$ years old): a cross-sectional statewide sample and oversamples of five specific ethnic and language groups. Analyses reported herein are based on responses provided by the 3,679 California adults who completed the random digit dial telephone interview: 603 nonHispanic Whites (16.9\%), 552 Blacks (15.0\%), 666 Hispanics (18.1\%), 618 Korean Americans (16.8\%), 622 Vietnamese Americans (16.9\%), and 618 (16.8\%) other Asian Americans.

After focus groups, pretesting, cognitive interviews, and translation and backtranslation 
to ensure comparability of forms, interviews were conducted in English, Spanish, Korean, and Vietnamese between April 2000 and March 2001. The samples were drawn by and data collection was conducted by the National Opinion Research Center (NORC) of the University of Chicago. (For details about the sample and data collection, please see Imhof, Murphy, \& Moore [2001].) The response rate was 51.5\%, which is comparable to other large, multi-lingual, statewide telephone surveys in the same locale (California Health Interview Survey, 2002; Weinbaum et al., 2001). The study was reviewed and approved by the IRBs of the university and NORC.

\section{Data Collection Instrument}

The data collection instrument was developed in consultation with a panel of seven community-based experts in IPV - survivors of IPV, directors of battered women's shelters and rape crisis hotlines, a facilitator of a male batterer group, and the creator of a rape prevention media campaign. The assistance of this group was enlisted to help the research be consistent with and relevant to community-based practice particularly as it relates to the ethnic groups under study. For example, they helped select concepts for and phrases and names used in the vignettes.

A fractional factorial design (e.g., Rossi \& Anderson, 1982) was used. Factorial designs use scenarios (vignettes) to describe a situation or event followed by a series of questions. The vignettes have variables in common and the variable categories are randomly assigned by the researcher. In addition, respondent characteristics are measured to assess how they are associated with the judgments. Fractional factorial designs, in which not all variables or all variable categories are used in each vignette, are an economical version of factorial designs. With prior planning, fractional factorial designs retain sufficient statistical power by which to examine all main effects, all two-way interactions, and some higher-order interactions. The main advantage 
is that more variables and variable categories can be examined without increasing sample size.

Each respondent was presented with seven vignettes; for the present investigation, we focus on the six vignettes about IPV among adults. Each vignette contained randomly assigned variable categories from up to 17 variables about the victim, the assailant, and the incident itself. The victim and assailant were always described as being of the same age and other characteristics (e.g., ethnicity, employment, alcohol use) were allowed to vary for the victim and assailant. In contrast to focusing on one type of abuse, which is common in much prior research, nine behaviors were used to illustrate a range of behaviors that can be considered psychologically, sexually, and physically abusive: belittled and insulted, said the victim could not have contact with anyone but the assailant, destroyed identification documents (social security card and driver's license if the victim was a U.S. citizen, green card if the victim was an immigrant), threatened to harm, pressured to have sex, forced to have sex, slapped, punched, and beat. The first vignette included randomly assigned categories of every variable, for example:

Fernando, a 35 year old Latino man who was born outside the U.S. but has been here a long time and is an office administrator, is living with Jim, a 35 year old White man who was born in the U.S. and is unemployed. One evening Jim accused Fernando of looking at another man. Then Jim grabbed an available object in a threatening manner and belittled and insulted Fernando. No children were around at the time. Before this happened, Jim drank heavily and Fernando had two drinks. This was one of many times that something like this had happened between them.

Subsequent vignettes used fewer variables and variable categories so as to reduce respondent and interviewer burden. Victim and assailant gender, ethnicity, and relationship status, motivation, and abuse type were included in every vignette because these variables were 
considered essential to the integrity of the vignettes. Apriori decisions were made to determine which variables to include in the scenarios based on the statistical power needed to ascertain differences based on the research question under study.

After each vignette, respondents were asked a series of questions related to norms about IPV (do you think the behavior is wrong?, do you think the behavior is illegal?, should it be illegal?) and the desired response of societal agents (should the police be called?, should a restraining order be issued?, should firearms be removed from [the assailant's] possession?, and, if the vignette included a child, should social workers be called to check on the children?). Refusals and "don't know" responses on these questions were rare, ranging from .08\% to $4.3 \%$. Statistical Analysis

Analyses are based on data related to six vignettes about IPV in adult couples - four male-on-female IPV, one female-on-male IPV, and one same-sex (about half were men and half were women) IPV - that were asked of each respondent. Analyses were limited to couples who were described as dating or living together because the categories of married and divorced generally do not apply to gays and lesbians. (Given that many long-term relationships of gays and lesbians are much like marriage, we also analyzed the data to compare cohabiting persons in a same-sex relationship to cohabiting and married persons in an opposite-sex relationship. The findings changed slightly in magnitude but not in direction, substance or statistical significance.)

The vignette was the unit of analysis, and the resulting sample size was 14,734 vignettes. Cell sizes vary because, as already noted, to reduce respondent burden, not all variables or variable categories were presented in each vignette.

Standard diagnostic statistics (correlation matrices, frequencies, tests for multicollinearity) were calculated for all predictor variables and found to be acceptable. General response patterns 
were examined through the use of univariate and bivariate statistics for each variable.

Multivariate logistic regressions took into account all vignette variables, respondent characteristics, and the nested nature of the design while assessing the effect of each predictor variable on the outcome variable. A Bonferroni correction for multiple comparisons was made, resulting in a $p$ level of $p<.000476$. Findings at or below the adjusted level of statistical significance are emphasized herein. The nested nature of the design (i.e., that each respondent judged multiple vignettes) was taken into account via the robust cluster option in STATA.

Results

Does Sexual Orientation (i.e., Same-vs. Opposite-sex) of the Couple Affect Judgments about IPV?

Bivariate analyses indicated differences in respondents' rating of IPV vignettes involving gay male and lesbian versus heterosexual couples. As shown in Table 1, participants differed on four of the seven outcomes: the behavior was wrong, police should be called, guns should be removed from the home, and a social worker should be called (when children were present). A higher percentage of respondents rated the behavior as wrong and that a social worker should be called when the violence occurred in gay male and lesbian (vs. heterosexual) relationships. A greater proportion of respondents thought the police should be called and that guns should be removed when the vignette involved a heterosexual (vs. a same-sex) couple. Although statistically significant, the differences were of relatively little substantive importance, particularly given that they do not take into account other variables.

Does Victim Gender Enter into Judgments about IPV in Same- and Opposite-Sex Relationships?

The role of victim gender, an important consideration in judgments about IPV, was obscured in considerations of sexual orientation alone. We, therefore, examined responses by gender and sexual orientation of the victim described in the vignette. The observed pattern of 
findings was consistent across outcome variables: heterosexual male victims were viewed differently than gay men, lesbians, and heterosexual women. For example, respondents were more likely to agree that the behavior should be illegal (i.e., an injunctive norm asserting what ought to happen) if the IPV victim was a heterosexual man (see Table 2). (Given that the vignette variables were assigned randomly, their inclusion in the analysis should change the findings little. A multivariate analysis including all vignette and respondent characteristics confirmed this supposition.) The pattern of findings lent support to the idea that some victims are considered more worthy than others.

The role of victim gender, sexual orientation, and their interaction was examined in multivariate analyses of respondent judgments about the IPV scenario. The bivariate analyses indicated that heterosexual men were less likely to be perceived as worthy victims, so they were used as the referent in multivariate analyses. As reported in Table 3, when all other vignette and respondent characteristics were taken into account, neither victim gender or sexual orientation of the couple was a statistically significant predictor of respondent judgments. The interaction of victim gender and sexual orientation was statistically significant in three judgments: whether the behavior was illegal, whether the behavior should be illegal, and whether a restraining order should be issued. For each, the adjusted odds ratio (AOR) was lower (i.e., considered in less need of intervention) when the IPV victims were heterosexual men compared to heterosexual women, lesbians, and gay men.

Although not reaching statistical significance, a few other substantive findings from this analysis merit mention. First, although the AOR was over 1.5, indicating that respondents were more likely to consider violence against women (than men) to be wrong, this judgment did not carry over to the legality of the behavior or what interventions should be brought to bear. All 
remaining AORs for gender vacillated around 1.0, which indicated that there was no difference between the groups. Likewise, although the AOR was nearly 2.0, indicating that respondents were more likely to consider violence in same-sex (vs. opposite-sex) relationships to be wrong, this judgment did not carry over to the legality of the behavior or what interventions should be brought to bear. One outcome variable - whether social workers should be called to check on the children, a question asked when the scenario reported that a child was in the other room during the incident - was in the opposite direction of (i.e., higher than) the remaining judgments about sexual orientation. This finding suggests that children may be perceived as needing particular protection if IPV occurs in same-sex relationships. And, finally, AORs were below 1.0 for every outcome variable for the interaction of victim gender and sexual orientation, indicating a general pattern of less harsh judgments and less desire for intervention when heterosexual men were the IPV victims.

Do Victim Sexual Orientation and Gender Affect The Contextual Characteristics That Are Taken Into Consideration in Judgments About IPV?

We turned next to the question of whether the variables taken into account when making judgments about IPV differ by victim gender and sexual orientation. We proceeded in two steps. First, we used multivariate logistic regression to identify vignette variables that predict and respondent characteristics that are associated with each outcome variable. Second, we compared the resulting AORs and their confidence intervals (CIs) to identify those that might differ significantly across the groups of interest (i.e., gender and sexual orientation group). The latter addresses our primary research question, namely, whether respondents used the same criteria when making judgments about male-on-female, female-on-male, lesbian, and gay male IPV.

Table 4 reports the AORs for all variables in which at least one variable category was a 
statistically significant predictor $(\mathrm{p}<.000476)$ of an outcome. Before describing patterns in the findings, we address the question of differences among the groups. As can be seen in Table 4, some variables were statistically significant for some groups but not others (e.g., in "behavior is illegal," the AOR for displaying a gun was elevated for all groups and statistically significant for three of the groups). However, rejecting the null hypothesis that any particular AOR is zero was not relevant when assessing differences among the groups. The issue is whether one can reject the null hypothesis that two or more AORs have a difference of zero.

None of the AORs differed significantly across the four groups, indicating that respondents took the same contextual factors into account when making judgments about IPV regardless of sexual orientation of the couple and gender of the victim. Given that the predictors for each outcome variable did not differ across the groups, it is appropriate to note the overall patterns in the findings. We proceed with that task, focusing on findings that reached statistical significance after the Bonferroni correction for multiple comparisons. For each, the described direction is straightforward: if the AORs are elevated, more respondents supported the examined outcome (e.g., the behavior should be illegal, a restraining order should be issued).

Various types of abuse garnered the largest AORs of all predictor variables. Beating (vs. belittling or insulting) an intimate partner showed the highest AORs and the most consistent pattern across the outcome variables; judgments about vignettes in which the intimate partner was punched or raped also were fairly consistent across outcome variables. These three behaviors were associated with substantially elevated AORs (up to 20.73) for respondents saying that the behavior is illegal, should be illegal, and that police should be called. These behaviors also were associated with elevated AORs for whether a restraining order should be issued, guns be removed, and social workers called. The AORs for less severe forms of maltreatment (i.e., 
pressure for sex, threatened to harm, destroyed identity documents) generally were elevated and statistically significant for each group in each outcome variable.

The presence of a gun significantly predicted participants' ratings for almost every group and outcome variable. Displaying a gun or a knife (compared to grabbing an available object in a threatening manner) was a consistent positive predictor of respondents reporting that the behavior was illegal, should be illegal, police should be called, a restraining order should be issued, and guns should be removed (AOR range $=2.44$ to $9.17, \mathrm{p}<0.000$ ). When a weapon was not mentioned, there was an overall trend of less support for any of the measured outcomes.

The frequency of the incident was a significant predictor of whether police should be called and whether a restraining order should be issued in male-on-female IPV. Respondents were more likely to think the police should be called if the incident was the fifth time, one of many times, and when frequency was not mentioned, compared to if the incident was described as the only time (AORs range from 1.58 to $2.06, \mathrm{p}<0.000$ ). Respondents were more likely to think a restraining order should be issued when the incident had occurred multiple times and when frequency was not mentioned in the vignette (AORs range from 1.45 to $2.41, \mathrm{p}<0.000$ ).

Assailant alcohol use was not a consistent predictor of the outcomes. Elevated and statistically significant AORs were noted for some of the outcomes when there was heavy drinking by the assailant in male-on-female IPV. Victim alcohol use was not a consideration in respondent judgments. Respondents were more likely to think a restraining order should be issued when the assailant and the victim were separated ( $\mathrm{OOR}=1.22$ ) as compared to when they were living together. (Data not tabled.)

What Respondent Characteristics Are Related to Their Judgments about IPV in Same-Sex and Opposite-Sex Relationships? 
Few respondent characteristics were associated with judgments about IPV (see Table 4). The patterns that emerged were related to male-on-female violence and to the question of whether firearms should be removed from the assailant's possession. And, as with the vignette variables, none of the statistically significant AORs differed from the nonsignificant AORs for the four groups of interest (i.e., gay, lesbian, male-on-female, and female-on-male IPV).

Statistically significant respondent characteristics generally were associated with elevated AORs for male-on-female IPV. Persons born outside the U.S. had a higher AOR of thinking that the behavior is illegal, should be illegal, and that firearms should be removed if the IPV was male-on-female. Blacks, Latinos, and Korean Americans were more likely than Whites to want firearms removed if the IPV was male-on-female. (Latinos and Korean Americans also were more likely to want firearms removed in gay male and female-on-male IPV.) A few respondent characteristics were associated with a lower AOR for male-on-female IPV, however. Korean Americans and Vietnamese Americans were significantly less likely to want the police to be called if the IPV was male-on-female. And men were less likely to want a restraining order to be issued if the IPV was male-on-female. Men also were substantially less likely than women to want firearms removed from the assailant regardless of the assailant's gender and sexual orientation. None of the findings reported in this paragraph differed across groups: the CIs for the statistically significant AORs overlapped with the CIs for the nonsignificant AORs.

\section{Discussion}

The concept of a "worthy victim" was borne out in this investigation of norms about intimate partner violence: gay men, lesbians, and heterosexual women were all viewed as more in need of societal protection and intervention than were heterosexual men. It appears that those who may be perceived as having less structural power are viewed as being more in need of 
societal assistance in IPV. We found little evidence to support our hypothesis that violence in gay male and lesbian relationships is evaluated differently than violence in heterosexual relationships. However, although all the behavior of the assailants was judged to be wrong nearly uniformly across the gender and sexual orientation groups, IPV against heterosexual men was judged differently in some regards: IPV against heterosexual men was less likely to be seen as illegal, that it should be illegal, and respondents were more likely to report that the police should be called and a restraining order should be issued. The pattern of findings is not consistent with prior research that indicates that persons from the dominant group are considered to be more worthy victims (Baldus et al., 1990). Instead, it lends some support to recent research (Lyons, 2008) that indicates that violence is rated as more serious if it involves minority victims, that is, women, ethnic minorities, and gay men and lesbians. The present investigation found gay men, lesbians, and heterosexual women to be considered more worthy victims in some regards; the victim's ethnicity did not affect respondent judgments about IPV nor did the assailant's ethnicity.

The context of the IPV was not taken into account differently based on sexual orientation of the couple and gender of the victim. For all groups, the threat of or the actual physical or sexual violence typically was perceived as a violation of norms and in need of intervention by social agents. And, finally, respondent characteristics generally were not associated with their judgments about IPV scenarios.

Findings imply that gay male and lesbian victims of IPV, rather than face additional stigma from the community at large, may be able to anticipate support similar to that extended to heterosexual women who are victims of IPV. This is not to assert that that the support extended to heterosexual female IPV victims is adequate but that an anti-gay or anti-lesbian bias was not observed in the present investigation. 
Changing norms about gay and lesbian relationships suggest that if same-sex intimate relationships continue to become more socially acceptable, a particular form of psychological maltreatment in IPV in lesbian and gay male relationships may become less potent, namely, the threat to disclose a closeted victim's sexual identity to family, friends, and coworkers (Renzetti, 1998). If gay male and lesbian victims of IPV face less homophobia, their sense of isolation and helplessness may be more similar to that of IPV victims in general. But special considerations remain.

Some societal responses to IPV in gay men and lesbians can be described as neglectful at best. Restraining orders, a legal remedy that is widely used when a victim is trying to end the relationship that requires the abuser to have either no or only peaceful contact with the victim (also known as protection from abuse orders, orders of protection, and stay-away orders), are not available to gay men and lesbians in seven U.S. states (Burke, Jordan, \& Owen, 2002). In addition, social services are not always welcoming; lesbian victims of IPV report not feeling comfortable seeking domestic violence services that generally are geared to heterosexual females (Renzetti, 1992). And most shelters do not accept male clients, making such services off limits to gay male IPV victims. Services specific to lesbian and gay male victims of IPV are reported to be positive and helpful (Bornstein, Fawcett, Sullivan, Senturia, \& Shiu-Thornton, 2006), but such resources are few relative to the need.

In addition, the concept of "mutual combat" has special parlance for gay men and lesbians. Law enforcement officers generally are trained these days to arrest the primary aggressor, the identification of whom is determined by untangling the history of the incident. But dual arrests (i.e., both parties are arrested) occur with some regularity in heterosexual IPV (Martin, 1997). Thus, the hesitance of some gay male and lesbian victims of IPV to call law 
enforcement for fear that officers will be unable or unwilling to differentiate between them and the abuser such that both victim and assailant are arrested may not be unfounded.

In the present investigation, wanting police summoned to the scene of an IPV incident did not differ for gay male, lesbian, heterosexual female, and heterosexual male victims. Prior research suggests that homophobia need not deter an appropriate police response to IPV in samesex couples (Younglove, Kerr, \& Vitello, 2002) but it appears that gay men and lesbians are unlikely to report incidents of IPV to police (Pattavina, Hirschel, Buzzawa, Faggiani, \& Bentley, 2007). In a recent study of 176,488 IPV incidents in the National Incident Based Reporting System database, far fewer than expected - less than $1 \%$ - of the incidents involved same-sex couples.

And, finally, society may expect gay male and lesbian victims of IPV to take certain courses of action as they attempt to end the violence. Although participants' willingness to get involved (i.e., to call the police or to serve as a trial witness) did not differ for gay male, lesbian, male-on-female, and female-on-male IPV (Poorman et al., 2003), recent vignette studies suggest that societal support for specific interventions following IPV may be linked to gender and sexual orientation. In one study, participants recommended calling the police or a hotline for male-onfemale IPV, but for female-on-male and same-sex IPV they recommended leaving the couple alone (Seelau \& Seelau, 2005). In another recent study (Taylor \& Sorenson, 2005), the likelihood that both partners were assigned fault for the IPV and responsibility for changing their situation was higher if the victims were gay men or lesbians (vs. heterosexual women). Couple-promoting actions were not valued when IPV occurred in same-sex relationships: Respondents were substantially less likely to want the couple to talk and substantially more likely to want the victim simply to leave the relationship. 
There are millions of lesbians and gay men in the U.S. and the world, and studying their family lives may challenge the heterosexism in family research and shed light on multiple aspects of family life in general (Allen \& Demo, 1995). However, such research is hampered by sampling difficulties, namely, the inability to obtain a high quality representative sample of sexual minorities in an economical manner. Moreover, investigations that use a large and diverse community-based sample and conduct interviews in multiple languages require substantial resources. In lieu of sufficient resources for studies specifically about the role of gender and sexual orientation in norms about IPV, a relevant vignette could be added to other ongoing research. Doing so would help elucidate the role of the study itself in shaping participant responses. The fact that all vignettes in the present study were about IPV may have implicitly guided respondents to think about the violence rather than victim or assailant characteristics. And the fact that a scenario with a heterosexual couple led the series of IPV vignettes may have affected judgments about the vignettes that followed. Additional research is needed to examine these possibilities.

Although limits continue, attitudes toward gay men and lesbians are more accepting and supportive than perhaps they ever have been in the U.S. Likewise, although the victim is still held accountable for stopping the violence (Taylor \& Sorenson, 2005), perceptions of IPV have become more sophisticated and less tolerant of abuse. Study findings suggest that members of the general population make few distinctions about IPV or what should happen after it occurs for gay men, lesbians, and heterosexual women. By contrast, heterosexual male victims of IPV are afforded less support in some regards than their gender and sexual minority counterparts. No other characteristics of the victim and assailant were important, and few characteristics of the respondents themselves were related to their judgments. For all victims, regardless of gender and 
sexual orientation, respondents focused primarily on the nature of the abusive behavior which, in a just world, is as it should be. 


\section{References}

Allen, K. R., \& Demo, D. H. (1995). The families of lesbians and gay men: A new frontier in family research. Journal of Marriage and the Family, 57, 111-127.

Baldus, D.C., Woodworth, G., \& Pulaski, P.A. (1990). Equal justice and the death penalty: A legal and empirical analysis. Boston: Northeastern University Press.

Bell, C. C. (1987). Preventive strategies for dealing with violence among blacks. Community Mental Health Journal, 23, 217-228.

Bornstein, D. R., Fawcett, J., Sullivan, M., Senturia, K. D., \& Shiu-Thornton, S. (2006). Understanding the experiences of lesbian, bisexual, and trans survivors of domestic violence: A qualitative study. Journal of Homosexuality, 51(1), 159-181.

Bradford, J., Ryan, C., \& Rothblum, E. D. (1994). National Lesbian Health Care Survey: Implications for mental health care. Journal of Consulting and Clinical Psychology, 62, $228-242$.

Brewer, P. R., \& Wilcox, C. (2005). Same-sex marriage and civil unions. Public Opinion Quarterly, 69, 599-616.

Burke, T. W., Jordan, M. L., \& Owen, S. S. (2002). A cross-national comparison of gay and lesbian domestic violence. Journal of Contemporary Criminal Justice, 18, 231-257.

California Health Interview Survey. (2002). CHIS 2001 methodology series -- Report 4: response rates. Los Angeles, CA: UCLA Center for Health Policy Research.

Craft, S. M., \& Serovich, J. M. (2005). Family-of-origin factors and partner violence in the intimate relationships of gay men who are HIV positive. Journal of Interpersonal Violence, 20, 777-791.

Diamant, A. L., Schuster, M. A., McGuigan, K., \& Lever, J. (1999). Lesbians'sexual history 
with men: Implications for taking a sexual history. Archives of Internal Medicine, 159, 2730-2736.

Diaz, R. M., Ayala, G., Bein, E., Henne, J., \& Marin, B. V. (2001). The impact of homophobia, poverty, and racism on the mental health of gay and bisexual Latino men: Findings from 3 U.S. cities. American Journal of Public Health, 91, 927-932.

Greenwood, G. L., Relf, M. V., Huang, B., Pollack, L. M., Canchola, J. A., \& Catania, J. A. (2002). Battering victimization among a probability-based sample of men who have sex with men. American Journal of Public Health, 92, 1964-1969.

Harris, R. J., \& Cook, C. A. (1994). Attributions about spouse abuse: It matters who the batterers and victims are. Sex Roles, 30, 553-565.

Herek, G. M., \& Glunt, E. K. (1993). Interpersonal contact and heterosexuals' attitudes toward gay men: Results from a national survey. The Journal of Sex Research, 30, 239-244.

Hicks, G. R., \& Lee, T. (2006). Public attitudes towards gays and lesbians: Trends and predictors. Journal of Homosexuality, 51(2), 57-77.

Imhof, L., Murphy, S. R., \& Moore, W. (2001). California Vignettes Study: Methodology Report. Chicago: National Opinion Research Center.

Letellier, P. (1994). Gay and bisexual male domestic violence victimization: Challenges to feminist theory and responses to violence. Violence and Victims, 9, 95-106.

Lewis, G. B. (2003). Black-White differences in attitudes toward homosexuality and gay rights. Public Opinion Quarterly, 67, 59-78.

Lie, G. Y., \& Gentlewarrier, S. (1991). Intimate violence in lesbian relationships: Discussion of survey findings and practice implications. Journal of Social Service Research, 15, (1/2) 41-59. 
Lockhart, L. L., White, B. W., Causby, V., \& Issac, A. (1994). Letting out the secret: Violence in lesbian relationships. Journal of Interpersonal Violence, 9, 469-492.

Lyons, C. J. (2008). Individual perceptions and the social construction of hate crimes: A factorial survey. The Social Science Journal, 45, 107-131.

Martin, M. E. (1997). Double your trouble: Dual arrest in family violence. Journal of Family Violence, 12, 139-157.

Mays, V. M., \& Cochran, S. D. (2001). Mental health correlates of perceived discrimination among lesbian, gay, and bisexual adults in the United States. American Journal of Public Health, 91(11), 1869-1876.

McClennen, J. C., Summers, A. B., \& Vaughan, C. (2002). Gay men's domestic violence: dynamics, help-seeking behaviors and correlates. Journal of Gay and Lesbian Social Services, 14(1), 23-49.

Merrill, G. S., \& Wolfe, V. A. (2000). Battered gay men: An exploration of abuse, helpseeking, and why they stay. Journal of Homosexuality, 39(2), 1-30.

Ohlander, J., Batalova, J., \& Treas, J. (2005). Explaining educational influences in attitudes toward homosexual relations. Social Science Research, 34, 781-799.

Pattavina, A., Hirschel, D., Buzzawa, E., Faggiani, D., \& Bentley, H. (2007). A comparison of the police responses to heterosexual versus same-sex intimate partner violence. Violence Against Women, 13, 374-394.

Pew Global Attitudes Project. (2003, June). Views of a changing world. Washington, D.C.: The Pew Research Center for the People and the Press.

Pew Research Center (2006, March). Less opposition to gay marriage, adoption and military service. Washington, D.C.: The Pew Research Center for the People and the Press. 
Poorman, P. B., Seelau, E. P., \& Seelau, S. M. (2003). Perceptions of domestic abuse in samesex relationships and implications for criminal justice and mental health responses. Violence and Victims, 18, 659-669.

Ratcliff, J. J., Lassiter, G. D., Markman, K. D., \& Snyder, C. J. (2006). Gender differences in attitudes toward gay men and lesbians: The role of motivation to respond without prejudice. Personality and Social Psychology Bulletin, 32, 1325-1338.

Renzetti, C. M. (1992). Violent betrayal: Partner abuse in gay and lesbian relationships. Newbury Park, CA: Sage.

Renzetti, C. M. (1998). Violence and abuse in lesbian relationships. In R. K. Bergen (Ed.), Issues in Intimate Violence (pp. 117-127). Thousand Oaks: Sage.

Rossi, P. H., \& Anderson, A. B. (1982). The factorial survey design: an introduction. In P. H. Rossi \& S. L. Nock (Eds.), Measuring social judgments: the factorial survey approach (pp. 15-67). Beverley Hills: Sage.

Schmitt, M. T., Lehmiller, J. J., \& Walsh, A. L. (2007). The role of heterosexual identity threat in differential support for same-sex 'Civil Unions' versus 'Marriages.' Group Processes \& Intergroup Relations, 10(4), 443-455.

Seelau, E. P., Seelau, S. M., \& Poorman, P. B. (2003). Gender and role-based perceptions of domestic abuse: does sexual orientation matter? Behavioral Sciences and the Law, 21, 199-214.

Seelau, S. M., \& Seelau, E. P. (2005). Gender-role stereotypes and perceptions of heterosexual, gay and lesbian domestic violence. Journal of Family Violence, 20, 363-371.

Taylor, C. A., \& Sorenson, S. B. (2005). Community-based norms about intimate partner violence: Putting attributions of fault and responsibility into context. Sex Roles, 53, 573- 
589.

Tjaden, P., Thoennes, N., \& Allison, C. J. (1999). Comparing violence over the life span in samples of same-sex and opposite-sex cohabitants. Violence and Victims, 14, 413-425.

Treas, J. (2002). How cohorts, education, and ideology shaped a new sexual revolution on American attitudes toward nonmarital sex, 1972-1998. Sociological Perspectives, 45, 267-283.

Weinbaum, Z., Stratton, T. L., Chavez, G., Motylewski-Link, C., Barrera, N., \& Courtney, J. G. (2001). Female victims of intimate partner physical domestic violence (IPP-DV), California, 1998. American Journal of Preventive Medicine, 21, 313-319.

Wilson, P. A., \& Yoshikawa, H. (2004). Experiences of and responses to social discrimination among Asian and Pacific Islander gay men: Their relationship to HIV risk. AIDS Education and Prevention, 16(1), 68-83.

Younglove, J. A., Kerr, M. G., \& Vitello, D. J. (2002). Law enforcement officers' perceptioncs of same sex domestic violence: Reason for cautious optimism. Journal of Interpersonal Violence, 17, 760-772. 
Table 1.

Respondent Ratings about Intimate Partner Violence, by Victim Sexual Orientation, \%

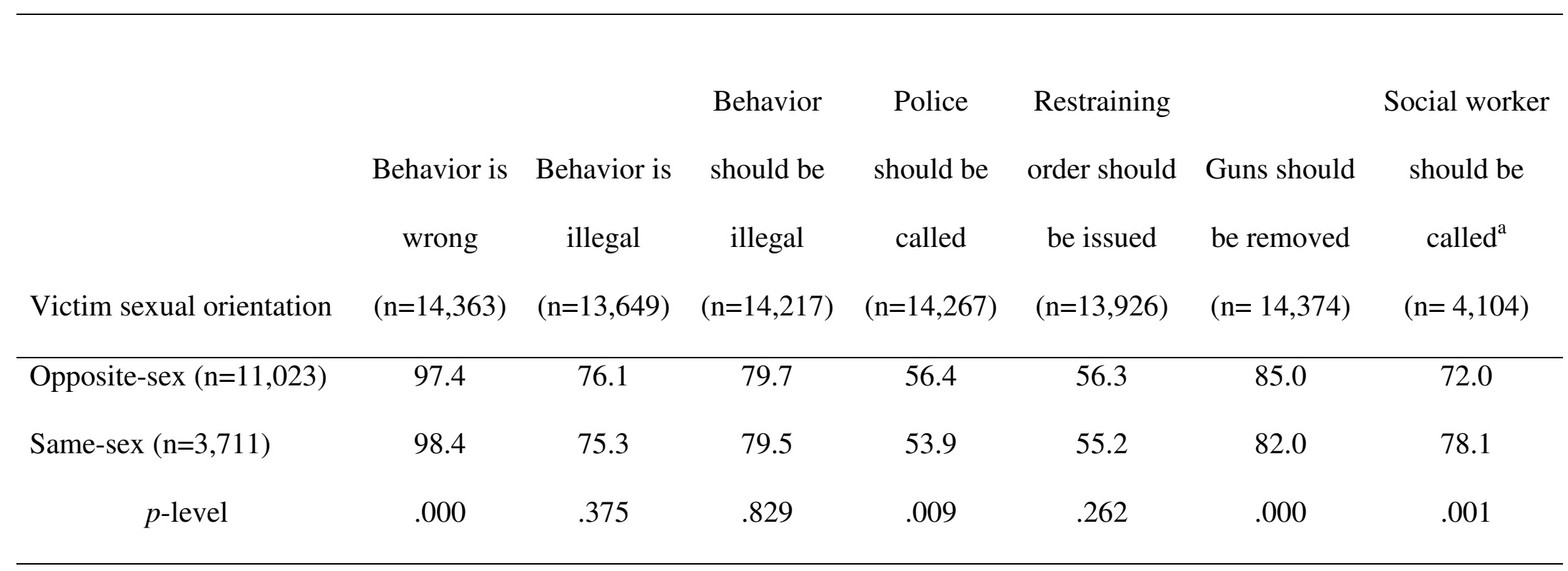

a Asked only if the vignette indicated that there was "a child in the other room during the incident." 
Table 2 .

Affirmative Responses to "Behavior Should be Illegal," by Victim Gender and Sexual Orientation, \%

\begin{tabular}{lcc}
\hline & \multicolumn{2}{c}{ Sexual orientation of couple } \\
\cline { 2 - 3 } & Opposite-sex & Same-sex \\
Victim gender & $(\mathrm{n}=10,719)$ & $(\mathrm{n}=3,498)$ \\
\hline Male $(\mathrm{n}=3,888)$ & 69.1 & 79.0 \\
Female $(\mathrm{n}=10,332)$ & 82.0 & 81.0 \\
\hline
\end{tabular}

Note. Responses for heterosexual male victims differed from the others $(p<.000476)$. 
Table 3.

Respondent Ratings of Intimate Partner Violence, by the Primary Variables of Interest, Adjusted Odds Ratios

\begin{tabular}{|c|c|c|c|c|c|c|c|}
\hline & & & & \multicolumn{3}{|c|}{ Restraining } & \multirow{2}{*}{$\begin{array}{c}\text { Social } \\
\text { worker } \\
\text { should be } \\
\text { called } \\
(\mathrm{n}=4,104)\end{array}$} \\
\hline & $\begin{array}{l}\text { Behavior } \\
\text { is wrong } \\
(n=14,252)\end{array}$ & $\begin{array}{l}\text { Behavior } \\
\text { is illegal } \\
(n=13,649)\end{array}$ & $\begin{array}{c}\text { Behavior } \\
\text { should be } \\
\text { illegal } \\
(\mathrm{n}=14,217)\end{array}$ & $\begin{array}{c}\text { Police } \\
\text { should be } \\
\text { called } \\
(\mathrm{n}=14,267)\end{array}$ & $\begin{array}{c}\text { order } \\
\text { should be } \\
\text { issued } \\
(n=13,926)\end{array}$ & $\begin{array}{c}\text { Guns } \\
\text { should be } \\
\text { removed } \\
(\mathrm{n}=14,374)\end{array}$ & \\
\hline Female $(n=10,640)$ (vs. male) & 1.54 & 1.02 & 1.05 & 0.98 & 1.07 & 0.97 & 0.83 \\
\hline Same-sex $(n=3,711)($ vs. opposite-sex $)$ & 1.96 & 0.85 & 0.91 & 0.83 & 0.94 & 0.78 & 1.44 \\
\hline Male, opposite-sex (n=2,024) (vs. others) & 0.80 & $0.47 *$ & $0.51 *$ & $0.45 *$ & $0.50 *$ & 0.70 & 0.76 \\
\hline \multicolumn{8}{|c|}{ frequency of incident. They also included the respondent characteristics of ethnicity, age, gender, nativity, current relationship status, } \\
\hline \multirow{2}{*}{\multicolumn{8}{|c|}{ ever married, ever divorced or separated, any children under age 5, any children ages 5-17, number of adults in household, education }} \\
\hline & & & & & & & \\
\hline$* p<.000476$ & & & & & & & \\
\hline
\end{tabular}


Views of Intimate Partner Violence 31

Table 4.

Respondent Ratings of Gay, Lesbian, Male-on-Female, and Female-on-Male Intimate Partner Violence, Adjusted Odds Ratios

\begin{tabular}{|c|c|c|c|c|c|c|c|c|c|c|c|c|}
\hline & & Behavior & is illegal & & & Should b & e illegal & & & Police & called & \\
\hline & $\begin{array}{c}\text { Gay } \\
(n=1,871)\end{array}$ & $\begin{array}{l}\text { Lesbian } \\
(\mathrm{n}=1,474)\end{array}$ & $\begin{array}{l}\text { Male-on- } \\
\text { Female } \\
(\mathrm{n}=8,407)\end{array}$ & $\begin{array}{l}\text { Female- } \\
\text { on-Male } \\
(n=1,875)\end{array}$ & $\begin{array}{c}\text { Gay } \\
(n=1,932)\end{array}$ & $\begin{array}{l}\text { Lesbian } \\
(n=1,561)\end{array}$ & $\begin{array}{c}\text { Male-on- } \\
\text { Female } \\
(n=8,766)\end{array}$ & $\begin{array}{l}\text { Female- } \\
\text { on-Male } \\
(n=1,946)\end{array}$ & $\begin{array}{c}\text { Gay } \\
(n=1,933)\end{array}$ & $\begin{array}{l}\text { Lesbian } \\
(\mathrm{n}=1,573)\end{array}$ & $\begin{array}{l}\text { Male-on- } \\
\text { Female } \\
(\mathrm{n}=8,783)\end{array}$ & $\begin{array}{l}\text { Female- } \\
\text { on-Male } \\
(n=1,970)\end{array}$ \\
\hline$\underline{\text { Vignette Variables }}$ & & & & & & & & & & & & \\
\hline Abuse type (vs. Belittled and insulted) & & & & & & & & & & & & \\
\hline Destroy documents $(n=1,683)$ & $2.75^{*}$ & 1.20 & $2.37 *$ & $3.75^{*}$ & $2.93 *$ & 2.27 & $2.52 *$ & $2.68 *$ & 1.09 & 1.02 & 1.28 & 0.65 \\
\hline Threaten to harm $(n=1,703)$ & 2.44 & $3.27 *$ & $2.14^{*}$ & $2.95 *$ & 1.99 & $2.82 *$ & $2.03 *$ & 2.29 & 1.65 & $2.85^{*}$ & $1.79 *$ & $2.58 *$ \\
\hline Pressure sex $(n=1,556)$ & $6.56^{*}$ & 1.90 & $4.28 *$ & $3.07 *$ & $4.91 *$ & 3.61 & $3.36^{*}$ & $2.36^{*}$ & $3.69 *$ & 1.74 & $2.40^{*}$ & 1.81 \\
\hline Rape $(n=1,658)$ & $7.07 *$ & $5.02 *$ & $9.93^{*}$ & $3.94 *$ & $8.05^{*}$ & $9.85^{*}$ & $8.78 *$ & $3.19 *$ & $3.04 *$ & $5.01 *$ & $4.84 *$ & 1.73 \\
\hline Slap $(n=1,593)$ & $3.35^{*}$ & $3.22 *$ & $5.61 *$ & $4.00^{*}$ & 2.68 & $4.14 *$ & $4.56^{*}$ & $2.72 *$ & 1.65 & $3.00 *$ & $2.50^{*}$ & 1.78 \\
\hline Punch $(n=1,591)$ & $13.26^{*}$ & $4.40^{*}$ & $9.73 *$ & $10.19^{*}$ & $13.37 *$ & $6.85^{*}$ & $7.86^{*}$ & $7.32 *$ & $5.57 *$ & $3.67 *$ & $4.87 *$ & $2.52 *$ \\
\hline Beat up $(n=1,692)$ & $10.66^{*}$ & $8.52 *$ & $17.66^{*}$ & $20.63^{*}$ & $9.74 *$ & $16.43^{*}$ & $11.05^{*}$ & $10.60 *$ & $5.94 *$ & $7.76^{*}$ & $8.13 *$ & $7.10^{*}$ \\
\hline Weapon (vs. Grabbed available object & & & & & & & & & & & & \\
\hline Knife $(n=2,086)$ & 3.11 & 1.85 & $1.82 *$ & 2.43 & 2.02 & 1.97 & $2.14^{*}$ & 2.38 & $2.89 *$ & 2.44 & $2.94 *$ & $3.74 *$ \\
\hline Gun $(n=2,129)$ & $5.82 *$ & 3.72 & $2.92 *$ & $8.35^{*}$ & $6.45^{*}$ & 5.10 & $2.49 *$ & $5.95 *$ & $4.65^{*}$ & $9.80 *$ & $3.41 *$ & $4.43^{*}$ \\
\hline No weapon mentioned $(\mathrm{n}=8,361)$ & 0.93 & 0.38 & 0.39 & $0.34 *$ & 1.65 & 0.40 & $0.35 *$ & $0.35 *$ & 0.97 & $0.42 *$ & $0.45^{*}$ & $0.47 *$ \\
\hline
\end{tabular}

Frequency of incident (vs. Only time) 
Views of Intimate Partner Violence 32

\begin{tabular}{|c|c|c|c|c|c|c|c|c|c|c|c|c|}
\hline Fifth time $(\mathrm{n}=2,098)$ & 1.44 & 1.77 & 1.33 & 1.01 & 1.51 & 1.31 & 1.37 & 0.92 & 1.59 & 1.97 & $2.06 *$ & 1.17 \\
\hline One of many times $(n=2,136)$ & 1.75 & 1.97 & 1.14 & 1.18 & 1.60 & 1.71 & 1.13 & 1.17 & 1.79 & 1.56 & $1.95 *$ & 0.89 \\
\hline No frequency mentioned $(\mathrm{n}=8,384)$ & 1.06 & 1.46 & 1.05 & 1.20 & 1.15 & 1.24 & 1.20 & 1.22 & 1.19 & 1.16 & $1.58 *$ & 1.00 \\
\hline \multicolumn{13}{|l|}{ Assailant alcohol use (vs. No drinks) } \\
\hline Had two drinks $(\mathrm{n}=2,142)$ & 0.50 & 1.51 & 1.22 & 0.84 & 0.60 & 1.25 & 1.06 & 0.63 & 0.68 & 0.77 & 1.31 & 1.03 \\
\hline Drank heavily $(\mathrm{n}=2,135)$ & 0.73 & 0.88 & $1.66^{*}$ & 0.91 & 0.83 & 1.04 & 1.47 & 0.82 & 0.79 & 1.30 & $1.60 *$ & 1.01 \\
\hline Drinking not mentioned $(n=8,324)$ & 0.71 & 1.19 & 1.30 & 0.89 & 0.84 & 1.09 & 1.21 & 0.68 & 1.00 & 1.12 & 1.21 & 0.97 \\
\hline \multicolumn{13}{|l|}{ Respondent Characteristics } \\
\hline \multicolumn{13}{|l|}{ Gender (vs. Female) } \\
\hline Male $(n=6,030)$ & 1.34 & 1.38 & 1.07 & 1.03 & 0.97 & 1.04 & 0.83 & 0.80 & 0.81 & 0.94 & 0.88 & 0.83 \\
\hline \multicolumn{13}{|l|}{ Race/Ethnicity (vs. White) } \\
\hline Black $(n=2,184)$ & 0.96 & 1.53 & 1.26 & 1.05 & 0.62 & 1.23 & 1.08 & 1.15 & 0.97 & 1.01 & 0.97 & 0.98 \\
\hline Latino $(n=2,683)$ & 1.52 & 1.86 & 1.56 & 1.38 & 1.10 & 2.07 & 1.45 & 1.35 & 1.21 & 1.30 & 1.45 & 1.09 \\
\hline Korean American $(n=2,435)$ & 0.92 & 1.21 & 1.02 & 0.90 & 0.79 & 0.93 & 0.78 & 0.99 & 0.76 & 0.54 & $0.54 *$ & 0.46 \\
\hline Vietnamese American $(n=2,435)$ & 1.97 & 2.27 & 1.17 & 1.09 & 1.88 & 2.67 & 1.10 & 1.52 & 1.67 & 0.88 & $0.54 *$ & 0.65 \\
\hline Other Asian American $(n=2,455)$ & 0.84 & 1.24 & 0.71 & 0.83 & 0.79 & 1.31 & 0.74 & 1.21 & 1.40 & 0.89 & 0.89 & 0.92 \\
\hline \multicolumn{13}{|l|}{ Nativity (vs. U.S. born) } \\
\hline Foreign-born $(\mathrm{n}=8,806)$ & 1.35 & 1.36 & $2.22 *$ & 1.77 & 1.17 & 0.97 & $1.55^{*}$ & 1.35 & 0.79 & 0.74 & 0.83 & 0.74 \\
\hline
\end{tabular}


Views of Intimate Partner Violence 33

Table 4. (continued)

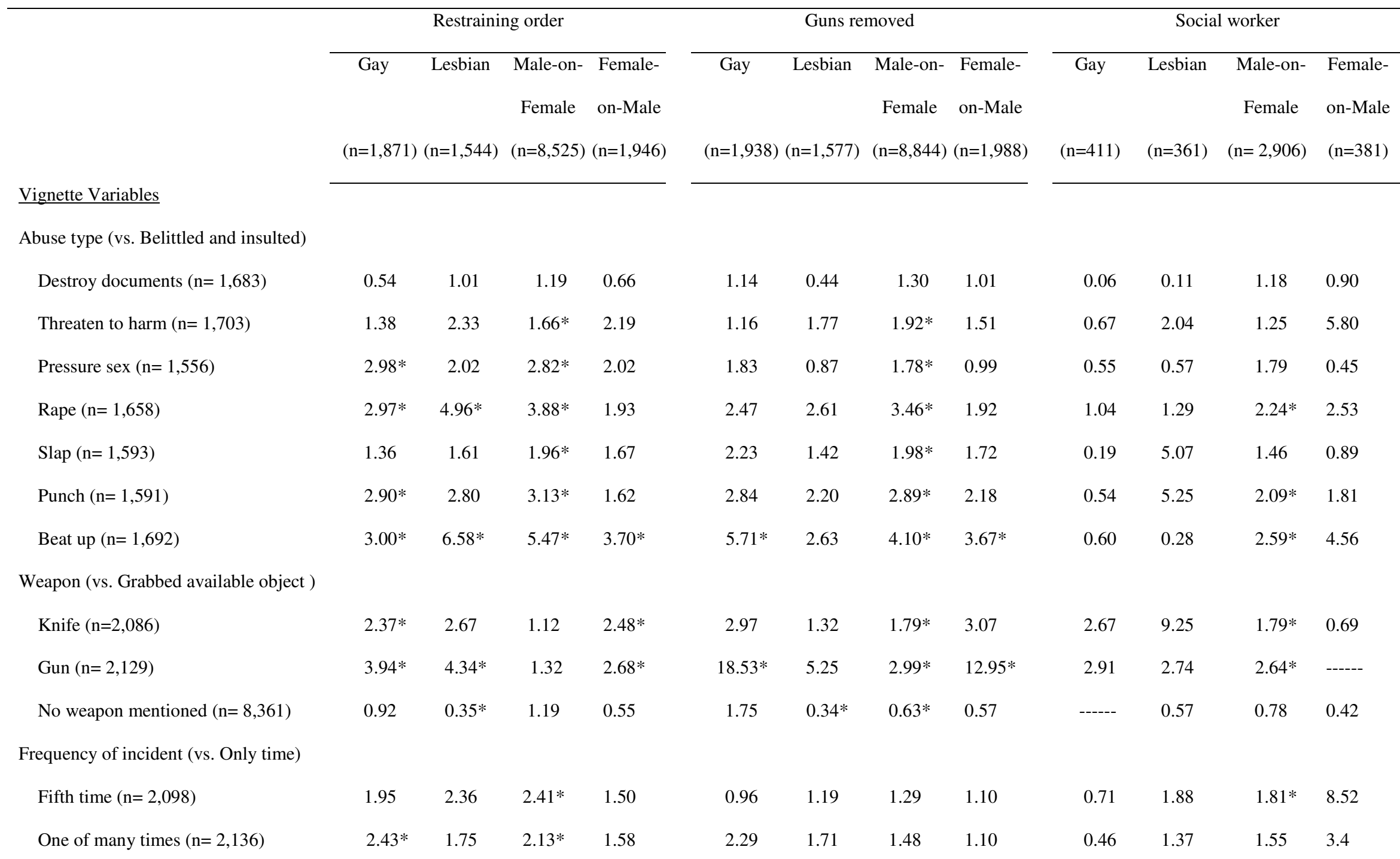


No frequency mentioned $(n=8,384)$

Assailant alcohol use (vs. No drinks)

Had two drinks ( $\mathrm{n}=2,142)$

Drank heavily $(n=2,135)$

Drinking not mentioned $(\mathrm{n}=8,324)$

$\begin{array}{llll}0.60 & 0.85 & 1.12 & 0.83 \\ 0.69 & 0.95 & 1.32 & 0.80 \\ 0.87 & 1.11 & 1.19 & 0.93\end{array}$

$\underline{\text { Respondent Characteristics }}$

Gender (vs. Female)

Male $(n=6,030)$

Race/Ethnicity (vs. White)

Black $(n=2,184)$

Latino $(n=2,683)$

Korean American $(n=2,435)$

Vietnamese American $(n=2,435)$

Other Asian American $(n=2,455)$

Nativity (vs. U.S. born)

Foreign-born $(\mathrm{n}=8,806)$

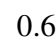

$0.67-0.96$

$0.78 *$

0.70

$\begin{array}{llll}1.17 & 1.31 & 1.33 & 0.96\end{array}$

$\begin{array}{llll}0.90 & 0.86 & 1.00 & 0.61\end{array}$

$\begin{array}{llll}1.99 & 1.84 & 1.02 & 0.77\end{array}$

$\begin{array}{llll}1.15 & 0.67 & 1.00 & 0.79\end{array}$

$0.45 *$

$0.43 *$

$0.42 *$

$0.44 *$

0.65

0.73

0.79

0.47

$1.97 \quad 1.58 \quad 1.94 * \quad 2.04$

$4.14 * \quad 2.39 \quad 2.72 * \quad 3.24 *$

$\begin{array}{llll}2.53 & 1.36 & 0.67 & 0.93\end{array}$

$\begin{array}{llll}2.40 & 1.17 & 2.15 & 2.91\end{array}$

$3.72 * \quad 1.77 \quad 3.13 * \quad 7.13 *$

$0.33 \quad 0.63$

$0.58 \quad 1.18$

$\begin{array}{llll}3.30 & 1.84 & 1.51 & 2.03\end{array}$

$0.52 \quad 0.58$

$0.50 \quad 1.73$

$\begin{array}{llll}2.46 & 0.94 & 1.56 & 2.38\end{array}$

$1.37 \quad 1.20$

$1.20 \quad 3.74$

Note: Regression models included the following vignette and respondent characteristic variables that were not statistically significant.

Vignette variables of victim and assailant ethnicity, victim and assailant socioeconomic status, victim and assailant nativity, child in next room, motivation, relationship status, victim alcohol use. Respondent characteristics of age, current relationship status, ever married, ever divorced or separated, any children under age 5, any children ages 5-17, number of adults in household, education level, size of town, employment status, income; number of people supported on income, and personally knows an IPV victim.

$p<.000476$ 